\title{
LOS DIOSES, EL GOBERNANTE Y LA COMUNIDAD. LAS ESTRATEGIAS POLÍTICO-RELIGIOSAS DEL GOBERNANTE 2 DE DOS PILAS, GUATEMALA
}

\author{
María Elena Vega Villalobos \\ Doctorado en Estudios Mesoamericanos, \\ Facultad de Filosofía y Letras, \\ Instituto de Investigaciones Filológicas, \\ Universidad Nacional Autónoma de México
}

\begin{abstract}
Resumen: Entre las características físicas más destacadas de la ciudad de Dos Pilas encontramos un extenso sistema de cuevas que fueron hábilmente incorporadas a la arquitectura pública. A pesar de que Dos Pilas ha sido identificado como uno de los señoríos más bélicos del periodo Clásico Tardío, en este artículo presento un análisis epigráfico de los monumentos erigidos durante el mandato del gobernante llamado Kokaaj K'awiil (quien reinó del 698 al 726 d. C.). Dichos restos señalan que esta ciudad, más que valerse de guerras y enfrentamientos para conseguir prestigio y poder en la región, conectó el ritual y la geografía sagrada para erigirse como una de las entidades políticas más destacadas del Petexbatún.
\end{abstract}

Palabras clave: Dos Pilas, epigrafía, Kokaaj K’awiil, ritual, cuevas.

ABSTRACT: Among the most outstanding physical features of the city of Dos Pilas is an extensive cave system which was skillfully incorporated into the public architecture. Despite the fact that Dos Pilas has been identified as one of the most warlike polities of the Late Classic period, this article presents an epigraphic analysis of the monuments erected during the reign of ruler Kokaaj K'awiil, in power between 698 and $726 \mathrm{AD}$, which point to the fact that this city, more than using wars and confrontations in order to gain prestige and power in the region, linked ritual and sacred geography in order to obtain its salient position as one of the most outstanding Petexbatun polities during this ruler's reign.

KeYwords: Dos Pilas, epigraphy, Kokaaj K'awiil, ritual, caves.

RECEPCIÓN: 21 de febrero del 2011.

ACEPTACIÓN: 28 de marzo del 2011. 



\title{
LOS DIOSES, EL GOBERNANTE Y LA COMUNIDAD. LAS ESTRATEGIAS POLÍTICO-RELIGIOSAS DEL GOBERNANTE 2 DE DOS PILAS, GUATEMALA
}

\author{
María Elena Vega Villalobos \\ Doctorado en Estudios Mesoamericanos, \\ Facultad de Filosofía y Letras, \\ Instituto de Investigaciones Filológicas, \\ Universidad Nacional Autónoma de México
}

\section{Introducción}

Entre 1990 y 1994, James E. Brady dirigió el equipo de reconocimiento e investigación de cuevas en la ciudad de Dos Pilas como parte del Proyecto Arqueológico Regional Petexbatún (Brady, 1995, 1997; Brady, et al., 1997). A través de extensos trabajos de exploración, mapeo y recolección de artefactos se reveló que las cuevas fueron determinantes en la construcción y orientación de la arquitectura pública de Dos Pilas: las estructuras del sitio y las diversas entradas a los conjuntos y complejos más destacados estuvieron alineadas a los sistemas de cuevas, como han constatado las excavaciones arqueológicas realizadas en los complejos de El Duende y Murciélagos (Demarest, 2006: 110-112; Demarest et al., 2003). Brady (1994) además, ha señalado que, debido a la presencia de una cantidad considerable de artefactos importados o realizados a partir de materiales foráneos hallados en las cuevas de Dos Pilas —donde se recuperaron numerosos tiestos cerámicos de diversas fases, concha, obsidiana, espejos de hematita y hueso trabajado-, se evidencia el papel destacado que tuvo el ritual dentro del intercambio interregional.

Las aportaciones de Brady han generado una serie de estudios relacionados con las cuevas y la política en Dos Pilas, pues en 2003 Arthur A. Demarest y otros investigadores estudiaron el papel del liderazgo político de los señores de este sitio adquirido a través de la geografía sagrada. En su artículo titulado "The Political Acquisition of Sacred Geography. The Murcielagos Complex at Dos Pilas" (Demarest, et al., 2003), los autores proponen, a partir del análisis específico del tercer complejo más importante de Dos Pilas, el Complejo Murciélagos, que los aspectos principales de la política estatal de la ciudad estuvieron basados en la geografía sagrada, la cual afianzó el poder real de los gobernantes de Dos Pilas y 
estructuró físicamente la relación entre diversos sectores sociales. Esta magnífica reconstrucción del engrandecimiento político a través de elementos religiosos, así como los resultados de Brady, nos invitan a reflexionar sobre los mecanismos político-religiosos de Dos Pilas y sobre los inicios de su liderazgo ritual en la región Petexbatún.

A partir de análisis específicamente epigráficos podemos estudiar el aspecto central que tuvo el rito en la conformación política de Dos Pilas. Me enfocaré en los textos producidos en las primeras décadas del siglo vil durante el reinado del Gobernante 2, llamado Kokaaj K'awiil, el cual es uno de los mejor documentados de la ciudad. Este dignatario gobernó a partir de la fecha 9.13.6.2.0, 11 Ajaw 18 Wo, 24 de marzo del 698 d. C., y murió en 9.14.15.1.19, 11 Kawak 17 Mak, 22 de octubre del 726 d. C. Su tumba, construida en el interior de la Estructura L5-1, es la única hasta ahora localizada de un gobernante de Dos Pilas (Demarest et al., 1991). Kokaaj K'awiil fue hijo de B'ajlaj Chan K'awiil (648-ca. 687 d. C.) y uno de los señores más destacados de la región Petexbatún.

Debido a que esta reconstrucción se basa principalmente en los datos obtenidos a partir de las inscripciones jeroglíficas, en muchas ocasiones me remitiré más a aspectos biográficos de los personajes que a consideraciones arqueológicas, pues el tema de la geografía sagrada de Dos Pilas ha sido investigado por diversos autores (ver Brady, 1994, 1995, 1997; Brady y Colas, 2005; Demarest, 2006). ${ }^{1}$

\section{La ciudad de Dos Pilas}

Dos Pilas se encuentra en el suroeste del Departamento del Petén, Guatemala (figura 1), en una subregión de la zona mayor del drenaje del río de la Pasión denominada Petexbatún, la cual abarca un área de $50 \mathrm{~km}^{2}$ (y presenta varios sitios prehispánicos, Houston, 1993: 10-11; Demarest, 2006: 15-17). La historia del señorío de Dos Pilas es una de las más breves hasta ahora conocidas de las ciudades mayas del periodo Clásico, y su fundación, al parecer, fue parte de una estrategia política de Tikal para mantener los ataques de Calakmul en esa zona a través de B'ajlaj Chan K'awiil, hijo del gobernante K'ihnich Muwaan Jol II de Tikal (Fahsen, 2002; Boot, 2002a, 2002b; Fahsen et al., 2003; Guenter, 2003; Demarest, 2004: 222-228, 2006: 136-141; Martin y Grube, 2008; Houston e Inomata, 2009: 109-111). Sin embargo, por razones que no han podido esclarecerse del todo, la dinastía tikaleña se dividió en las primeras décadas del siglo vil. La pequeña

\footnotetext{
${ }^{1}$ Me parece importante señalar que este aspecto de la geografía sagrada ha sido trabajada desde diversos enfoques y disciplinas, pero no desde el terreno epigráfico. Aunque contamos con interesantes aportaciones en la contextualización epigráfica de los señores de Dos Pilas (ver, por ejemplo, Houston, 1993; Fahsen, 2002; Boot, 2002a, 2002b; Guenter, 2003 y Martin y Grube, 2000, 2008), hasta ahora no se ha analizado el tema de la geografía sagrada a partir de la lectura de los textos jeroglíficos del sitio. Por esa razón, el lector encontrará una reconstrucción basada en los textos más que en la evidencia arqueológica.
} 


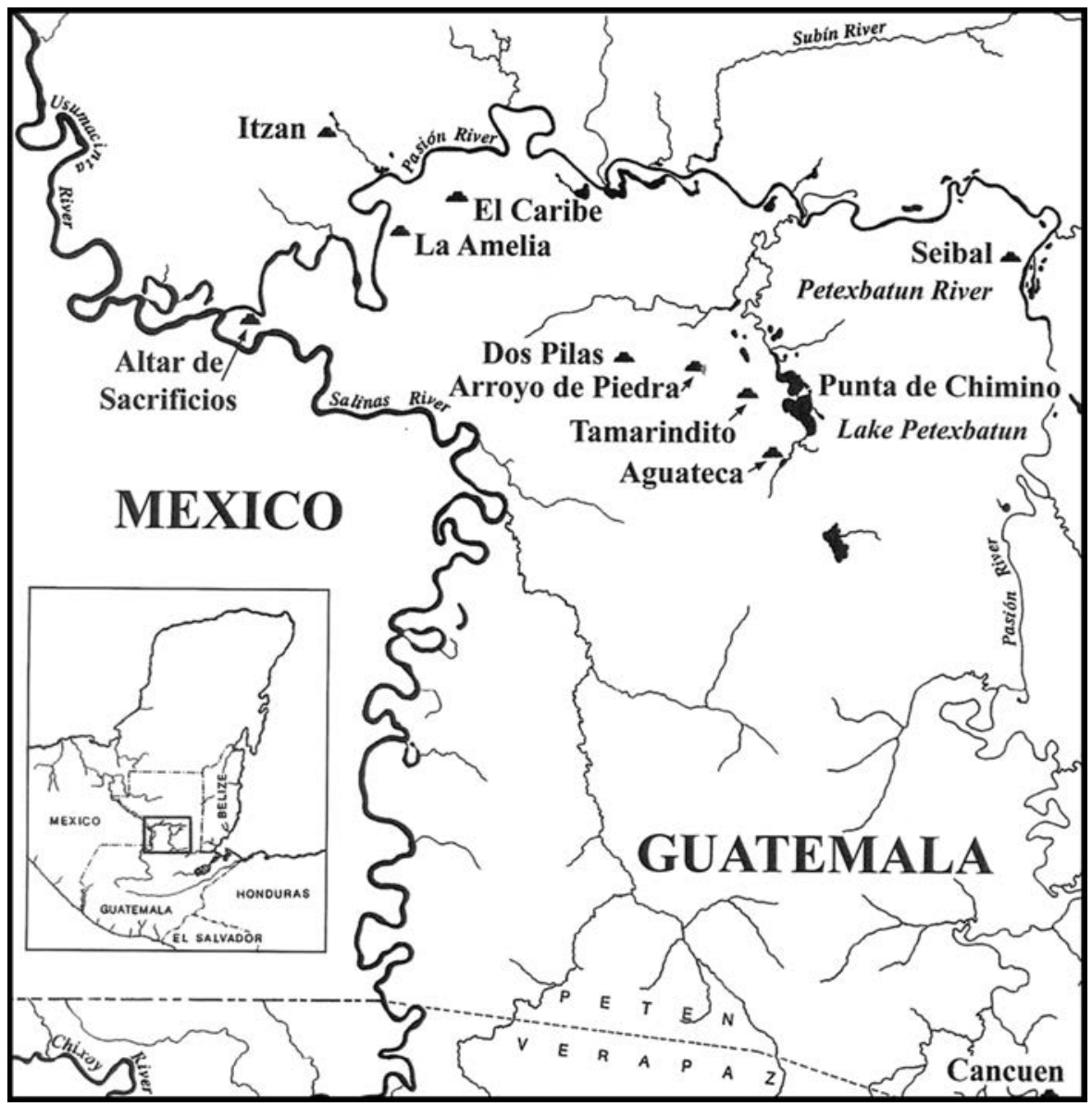

Figura 1. Mapa de la región Petexbatún que muestra la ubicación de Dos Pilas.

Tomado de Demarest, 2006

ciudad de Dos Pilas, bajo el mando de B'ajlaj Chan K'awiil y apoyado por el gobernante Yuhkno'm Ch'e'n de Kanu'l —Calakmul—, se enfrentó en numerosas ocasiones al señor de Tikal, llamado Nu'n Jol Chaahk ${ }^{2}$ ( $c f$. escaleras jeroglíficas 2 y 4 de Dos Pilas). Esta cruenta lucha terminó en el año 679 d. C., cuando B’ajlaj Chan K'awiil derrotó e inmoló al gobernante tikaleño.

Después de esta abrumadora victoria, B'ajlaj concentra sus esfuerzos en la construcción de su ciudad, sobre todo en lo que ahora conocemos como la Plaza

\footnotetext{
${ }^{2}$ Este gobernante también es llamado Nuun Ujol Chaahk en varios trabajos.
} 
Principal, donde adosó a los edificios realizados bajo su mandato una serie de paneles y escaleras jeroglíficas que narran diversos aspectos de su vida política. En otro trabajo (Izquierdo y Vega, 2009) he señalado que, muy probablemente, B'ajlaj no pudo expandir su dominio por sí solo, pues el progreso de Dos Pilas no se hubiera producido de no existir ventajas perceptibles para otros señoríos y grupos de poder. La participación de éstos en las metas de Dos Pilas pudo estar inspirada en una distribución más amplia de beneficios, donde Dos Pilas aportó prestigio y la experiencia de una mayor complejidad sociopolítica, mientras que Arroyo de Piedra, Tamarindito y Aguateca - los señoríos más destacados de la región antes de la llegada de B’ajlaj- legitimaron socialmente su estancia en el Petexbatún y aportaron bienes económicos necesarios para la subsistencia de Dos Pilas.

Entre las ligas políticas que consolidaron la estancia de la dinastía Mutu'l en la región encontramos la unión de B’ajlaj, primero, con una mujer de la ciudad de Itzán, con quien procreó al parecer dos hijos: Kokaaj K'awiil y el Gobernante $3^{3}$ —su nombre aún no está totalmente descifrado—. Y con una señora identificada como Ix B'ulu', quizá miembro de un linaje local, con quien procreó a Ix Chan Wut? Ajaw, mejor conocida como la señora Seis Cielo (Houston, 1993; Martin y Grube, 2008). Aunque aún no se ha encontrado una referencia a la muerte de B’ajlaj, sus últimos actos se fechan en 686 d. C., razón por la cual se mencionan distintas fechas para su deceso; estas oscilan entre el 692 y el 697 d. C. Es muy probable que una de las estructuras del Complejo Murciélagos resguarde su tumba (Demarest, comunicación personal, 2011).

Entre los años 692 y 698 d. C. tenemos un vacío en las inscripciones de Dos Pilas. En la parte final de la Escalera Jeroglífica 2 (Escalón 6, sección oeste) es mencionado un personaje llamado Itzam Kokaaj B'ahlam seguido de las expresio-

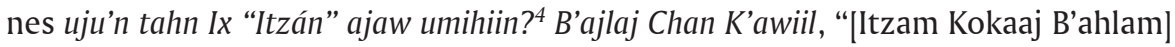
es la imagen querida de la señora de Itzán [e] hijo de B’ajlaj Chan K’awiil”. Esta referencia aún crea desconcierto, pues sugiere que posiblemente B'ajlaj tuvo un sucesor directo (Martin y Grube, 2008: 58) con un mandato muy breve y que no fue quien hoy conocemos como Gobernante 2. O, como ha sugerido Houston (1993: 108), puede tratarse del nombre de preascensión del mismo Gobernante 2. Sea como fuere, lo cierto es que este personaje no vuelve a ser mencionado en los textos de Dos Pilas.

\footnotetext{
${ }^{3}$ Diversos autores proponen que el Gobernante 3 de Dos Pilas (726-741 d. C.) fue hijo de Kokaaj K'awiil. Sin embargo, debido a registros jeroglíficos que comentamos en este trabajo, me parece más probable que el Gobernante 3 fuera hijo de B'ajlaj Chan K'awiil.

${ }^{4}$ La lectura del relacionador de parentesco umihiin, "hijo de [varón]", aún es incierta, razón por la cual le agrego un signo de interrogación.
} 


\section{El gobernante Kokaaj K’awiil}

Stephen Houston y Peter Mathews (1985: 15) llamaron a este personaje "Gobernante 2" (figura 2) en su reconstrucción inicial de la secuencia dinástica de

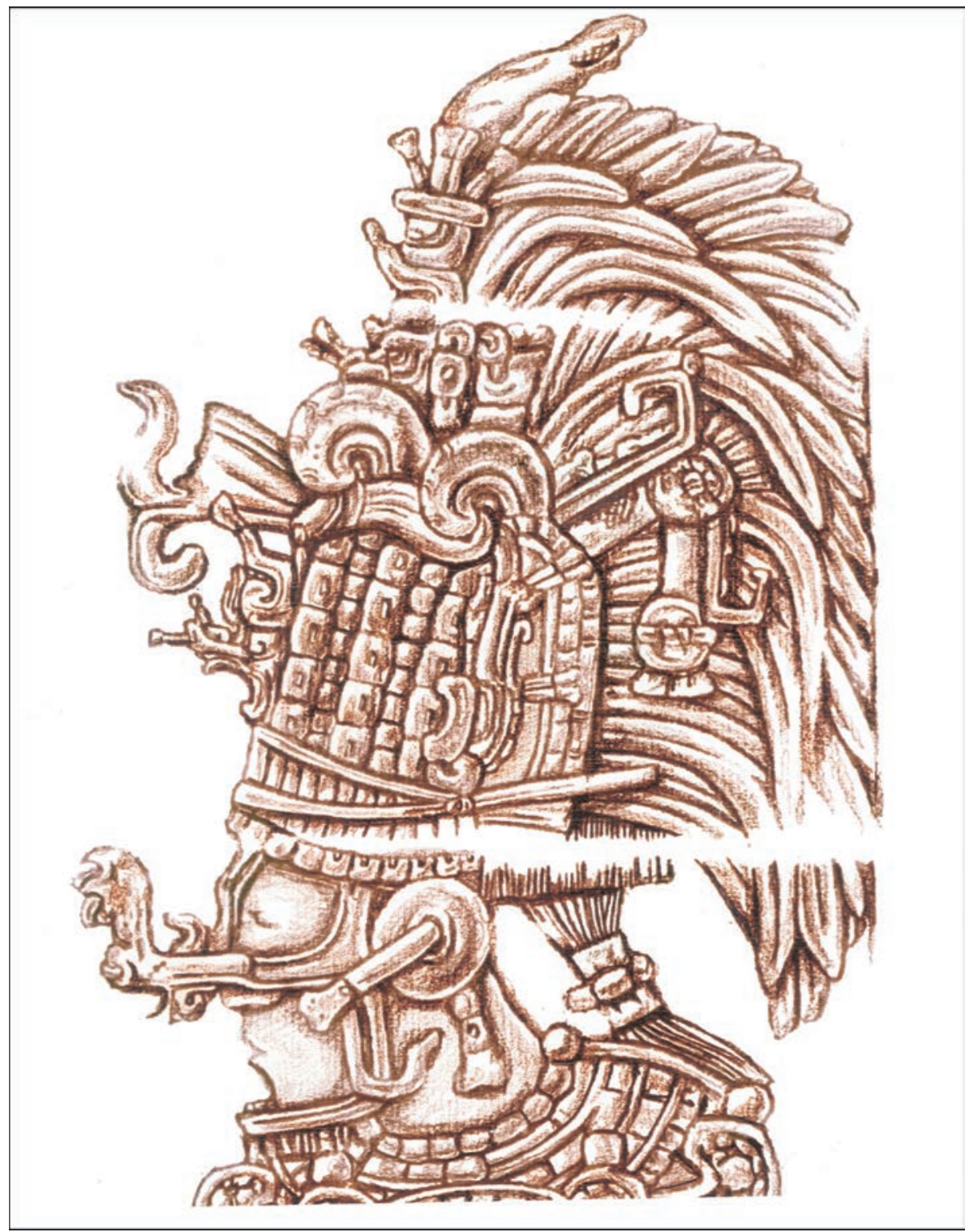

Figura 2. El gobernante Kokaaj K'awiil. Detalle de la Estela 11 de Dos Pilas. Dibujo de Moisés Aguirre basado en Houston, 1993 
Dos Pilas, un apelativo que siguió utilizándose años después de esa publicación (Stuart y Houston, 1994). En un estudio posterior, Simon Martin y Nikolai Grube (2000: 58) lo identificaron como Itzamnaaj K'awiil, debido a que su cláusula nominal incluía los glifos de los dioses D (Itzamnaaj) y K (K’awiil) de la clasificación de Paul Schellhas. Estudios recientes (Martin, 2006; Boot, 2008) señalan que el nombre completo de la deidad ave principal, el dios D, fue Yax Kokaaj Muut y, entre los glifos que componen su nombre, encontramos un signo en forma de medallón que, según Martin (2006: 18-19), es el apelativo de este dios: kokaaj, el cual se traduce como "luciérnaga". Debido a que numerosos teónimos de los gobernantes mayas del Clásico incorporan este signo-medallón, ahora los leemos como Kokaaj y no como Itzamnaaj. Así, el nombre del Gobernante 2 de Dos Pilas, al incorporar en todos sus registros jeroglíficos nominales el medallón y el logograma K'AWIL, fue Kokaaj K'awiil (figura 3).

La fecha de nacimiento de Kokaaj K'awiil la encontramos en la parte posterior de la Estela 8, un monumento erigido por su sucesor y hermano menor después de su muerte. La fecha, registrada en el sistema de Cuenta Larga (figura 4), es 9.12.6.15.11. Sin embargo, esta fecha daría como resultado la Rueda de Calendario 11 Chuwen 4 Zip con el quinto Señor de la noche. A pesar de que la Cuenta Larga es 9.12.6.15.11, en los bloques B5, A6 y A8 tenemos, respectivamente, el día 13 Chuwen, G4 (el Señor de la noche) y el mes 19 K'ayab'. Debido a que en el análisis epigráfico se opta por el menor error en las reconstrucciones calendáricas, seguimos la propuesta de Peter Mathews (2001: 397-398): que la fecha correcta en Cuenta Larga es 9.12.*0.*10.11, 13 Chuwen 19 K'ayab', 25 de

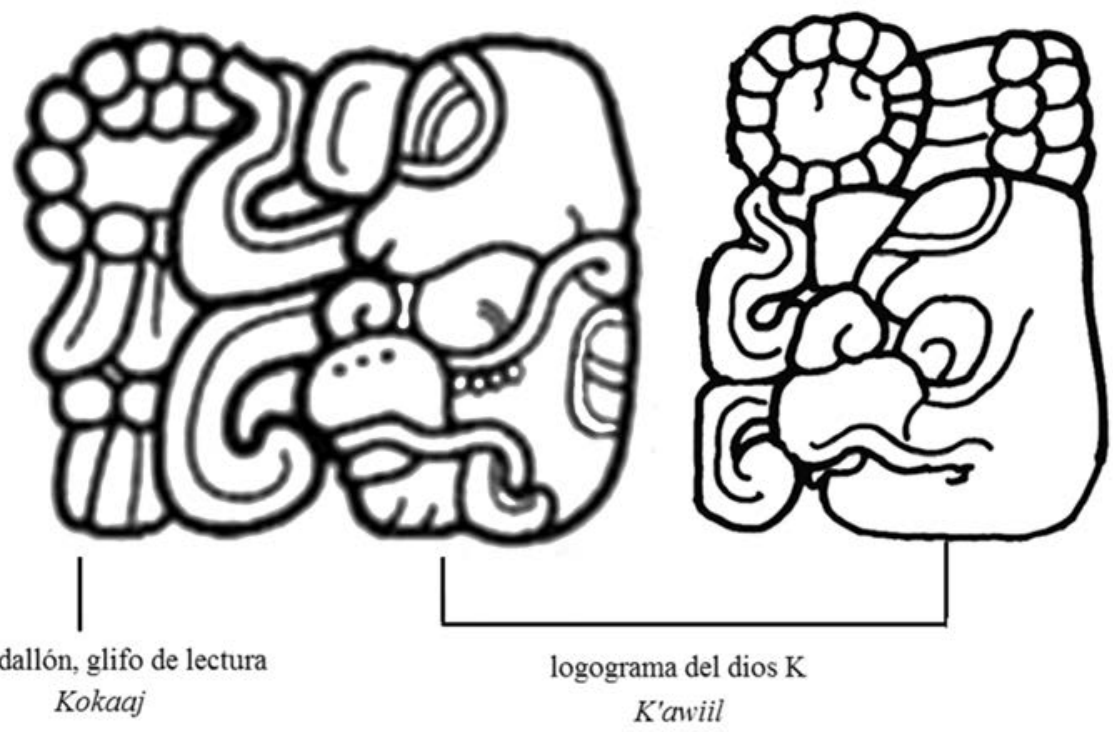

FiguRA 3. Ejemplos del nombre Kokaaj K'awiil 


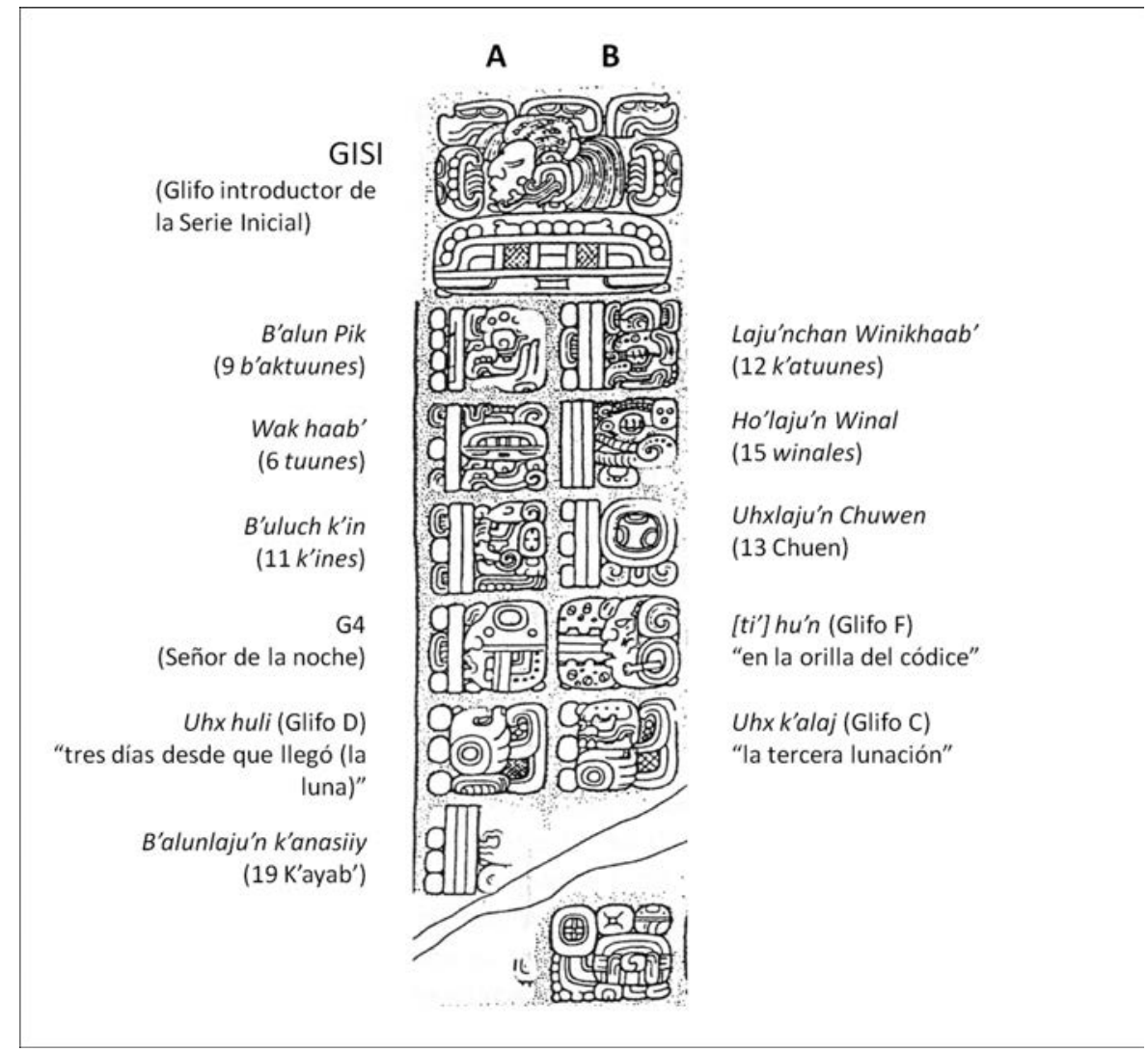

Figura 4. Detalle de la Estela 8 de Dos Pilas que registra el nacimiento de Kokaaj K'awiil. Dibujo de Houston, 1993

enero de 673 d. C. Esta discrepancia entre la Cuenta Larga y la Rueda de Calendario ha sido interpretada por Martin y Grube (2008: 59) no como un error de cálculo, sino como un cambio intencional para ocultar el lugar extranjero de nacimiento de Kokaaj K’awiil.

Esta propuesta es muy convincente si contextualizamos el nacimiento de Kokaaj K'awiil dentro de las cruentas batallas que protagonizó su padre, B’ajlaj Chan K'awiil, contra Nu'n Jol Chaahk, gobernante de Tikal. El Escalón 1 de la sección oeste de la Escalera Jeroglífica 2 (figura 5a) registra un ataque de "guerraestrella" 5 contra la ciudad de Dos Pilas que obliga a B'ajlaj a refugiarse en un sitio llamado Chaahk Naah, "Casa del dios Chaahk" —un sitio aún no identificado-, en la fecha 9.12.0.8.3, 8 de diciembre de 672 d. C. Debido a que el siguiente es-

${ }^{5}$ El glifo denominado "guerra-estrella" es un verbo en voz medio pasiva que no ha podido ser descifrado. Sin embargo, sabemos que hace referencia a guerra y ataque. 


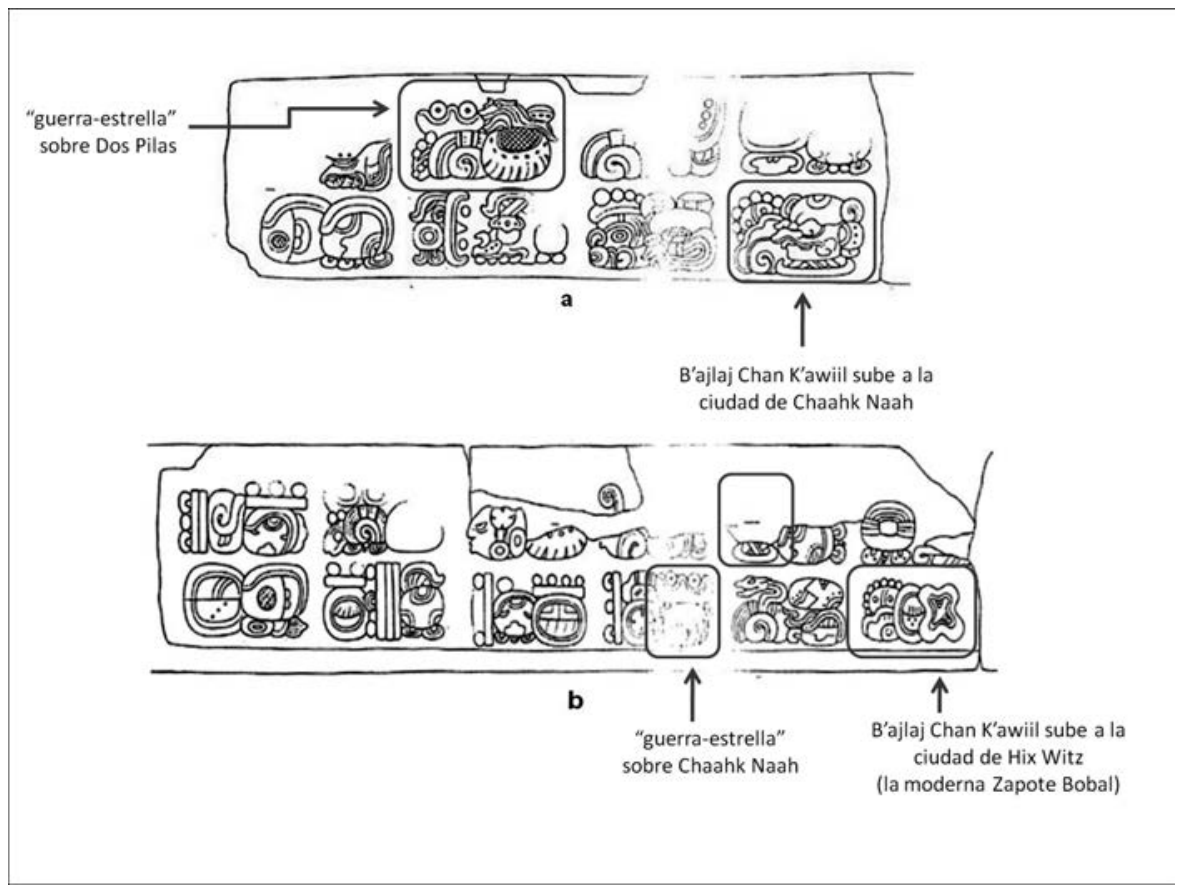

Figura 5. Diversos ataques contra B’ajlaj Chan K'awiil registrados en la Escalera Jeroglífica 2 de Dos Pilas. Dibujos de Fahsen, 2002

calón (figura 5b) narra otro ataque a Chaahk Naah en la fecha 9.12.1.0.3, 9 Akb’al 6 Yaxk'in, 26 de junio de 673 d. C., podemos considerar que si la señora de Itzán siguió a B’ajlaj a sus diversos refugios, Kokaaj K'awiil nació en Chaahk Naah.

La misma Estela 8 registra que en 9.13.6.2.0, 11 Ajaw 18 Wo, 24 de marzo de 698 d. C., Kokaaj K’awiil (figura 6) chumwaan ti ajawlel, "se sentó o inició en el señorío" cuando tenía un poco más de 25 años; ese mismo día uch'amaw xo[llte', ${ }^{6}$ recibió el báculo o cetro en presencia de los Dioses Remeros, K’awiil? y Chaahk en el centro de la ciudad (tahn ch'e'n) de Dos Pilas.

Tres años antes de que Kokaaj K'awiil se entronizara, en el año 695 d. C., el gobernante de Calakmul, llamado Yuhkno'm Yihch'aak K'ahk', fue derrotado por el hijo del desafortunado Nu'n Jol Chaahk, Jasaw Chan K'awiil, quien conmemoró este triunfo en una serie de dinteles de madera colocados en el interior del Templo I. Este evento es importante, pues uno de los primeros grandes sucesos del reinado de Kokaaj K'awiil lo encontramos en la Estela 1, donde se dice que Dos Pilas volvió a enfrentarse a Tikal en 9.13.13.0.2, 17 de junio del 705 d. C. Entonces un señor de este sitio fue derrotado por un personaje que desde ese

${ }^{6}$ La palabra xolte' es traducida por los epigrafistas como "báculo" o "cetro" y se relaciona con la toma de poder de diversos gobernantes mayas. 


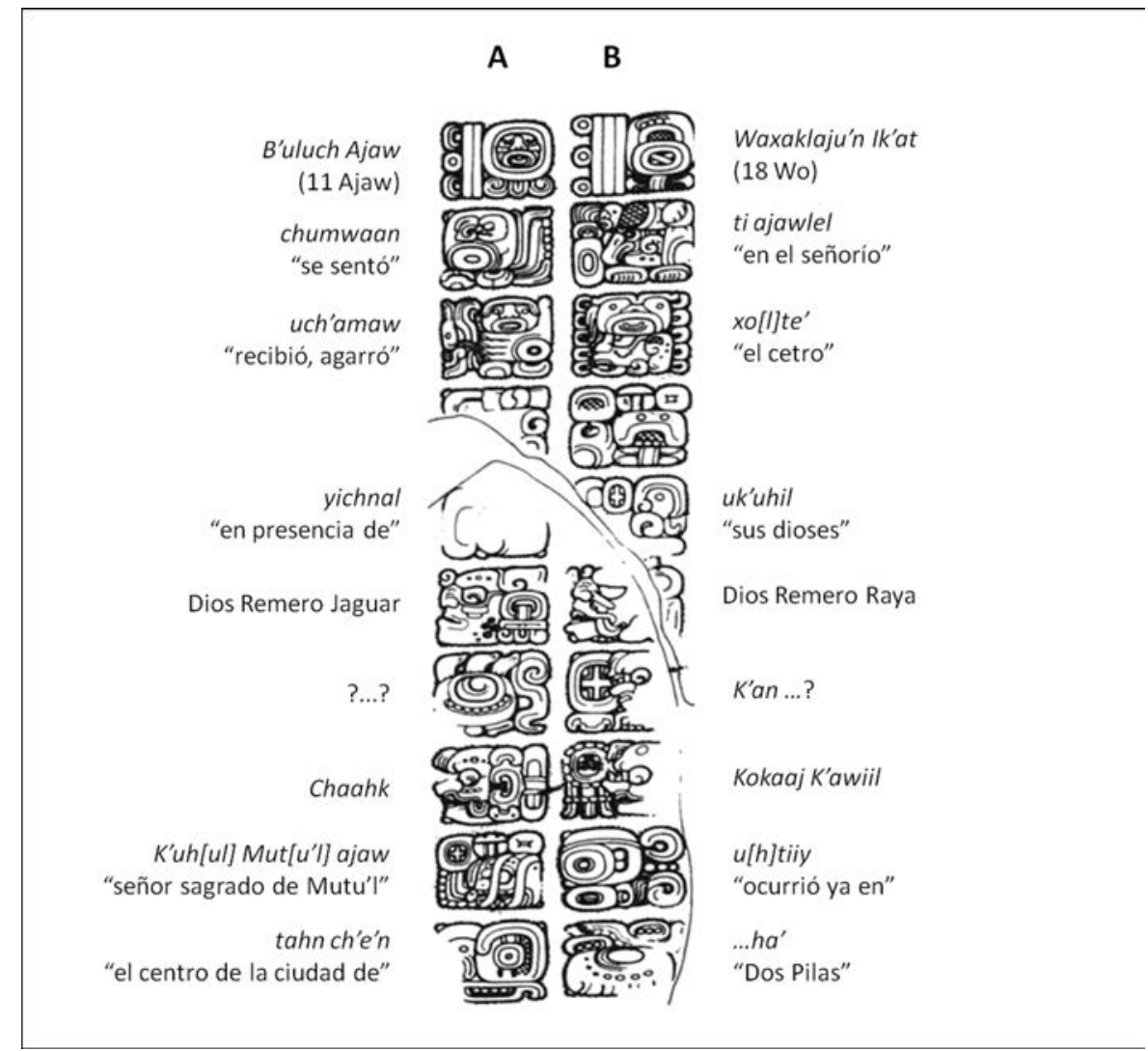

Figura 6. Estela 8 de Dos Pilas que registra la entronización del gobernante Kokaaj K'awiil. Dibujo de Stephen D. Houston, 1993

momento ostentó el título de ucha'n K'in B'ahlam, “el guardián de K’in B’ahlam”, el hermano menor de Kokaaj K'awiil quien a su muerte heredó el trono de Dos Pilas: el Gobernante 3.

Esta victoria de Dos Pilas ante un renovado Tikal no sólo reafirmó su superioridad bélica, sino que inauguró todo un programa político sin paralelo en el Petexbatún, donde diversos lugares sagrados, danzas, ritos y sacrificios se consagraron e institucionalizaron, convirtiendo a la ciudad de Dos Pilas en el respaldo ideológico de la región.

\section{Los monumentos de Kokaaj K’awiil}

Los monumentos que podemos adjudicar con certeza a Kokaaj K'awiil son las estelas 1, 11, 12, 13, 14, 15 y 16, así como los paneles 1 y 2 . La Escalera Jero- 
glífica 1, aunque menciona algunos eventos realizados por este gobernante, al parecer fue elaborada durante el reinado del gobernante 4, llamado K'awiil Chan K'ihnich. Debido a que la Escalera Jeroglífica 1 no fue concluida se ha planteado la posibilidad de que su ejecución fue suspendida a la muerte de Kokaaj K'awiil. Sin embargo, los pocos cartuchos jeroglíficos que aún se conservan indican que el personaje principal del texto de esta escalera es K'awiil Chan K'ihnich, razón por la cual Martin y Grube (2008: 63) sugieren que el monumento quedó inconcluso debido a la derrota de Dos Pilas ante Tamarindito en el año $761 \mathrm{~d}$. C.

Las estelas de Kokaaj K'awiil conmemoran periodos de ho' tuun, pues fueron elaboradas cada cinco años a partir de 706 d. C., 9.13.5.0.0, hasta el 721 d. C., 9.14.10.0.0. En cuanto a su diseño, las estelas de este gobernante lo representan de pie con la cabeza girada hacia su costado derecho (figura 7) y con muy

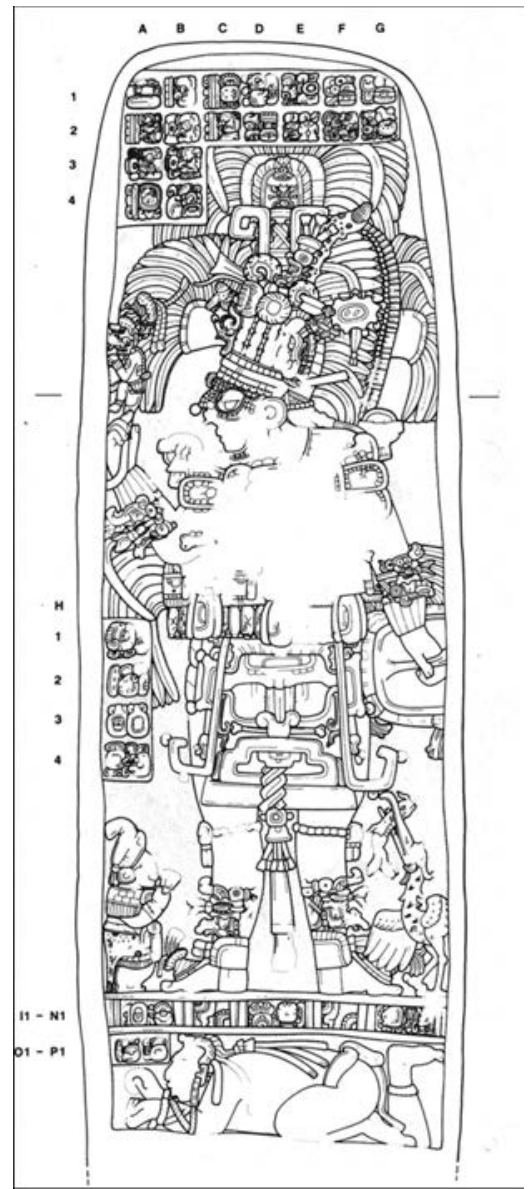

Figura 7. Estela 14 de Dos Pilas. Dibujo de Houston, 1993 
poca comunicación con otros elementos que conforman la escena, ya sean aves, enanos o cautivos. Todos están colocados en superposición de planos, donde el cautivo fue ubicado en el más bajo, las aves y enanos a los pies del personaje y el gobernante dominando la representación, pues el tamaño indica la elevada jerarquía del dignatario.

\section{El complejo de El Duende}

Uno de los complejos ceremoniales más importantes de Dos Pilas es el conjunto denominado El Duende (figura 8a), el cual fue construido durante los primeros años del reinado de Kokaaj K'awiil. Ubicado a $1 \mathrm{~km}$ al este de la Plaza Principal de Dos Pilas, este complejo (Escobedo, Robles y Wright, 1992; Escobedo, 1994; Brady, 1997; Demarest et al., 2003; Brady y Colas, 2005) se alza sobre la porción más alta del sitio, en un cerro natural de roca caliza, y comprende una escalinata, cinco terrazas y un conjunto habitacional, así como varios monumentos tallados.

La selección de este terreno para la construcción de tan importante complejo no fue casual, pues el proyecto arquitectónico de los señores de Dos Pilas incorporó las dos cuevas adyacentes: la primera de ellas se encuentra debajo del cerro y ha sido llamada Cueva del Río el Duende debido al extenso lago subterráneo

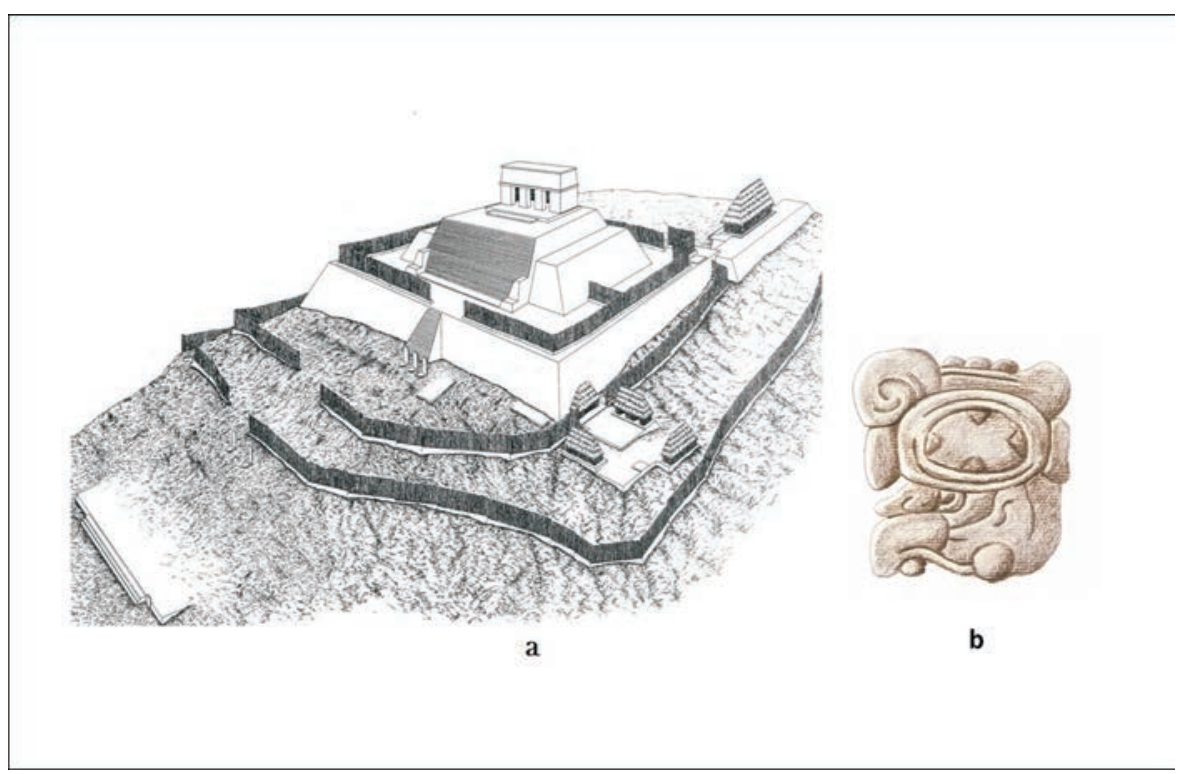

Figura 8. a) Reconstrucción de la pirámide El Duende. Tomado de Demarest, 2006.

b) Topónimo K'ihnha'nal, "el lugar del agua caliente", antiguo nombre del complejo.

Dibujo de Moisés Aguirre basado en Houston, 1993 
que alberga. El grupo habitacional fue construido encima de la cámara principal de la segunda cueva, denominada Cueva de El Duende, de donde se han recuperado fragmentos cerámicos fechados en el periodo Preclásico Tardío, así como uno de los textos dinásticos más tempranos de la ciudad de Dos Pilas (Houston, 1993: 102; Brady y Colas, 2005: 153). En la tercera terraza del conjunto fueron colocadas las estelas 14 y 15; en la primera las estelas 11,12 y 13 , y en el templo central se adosaron los paneles 15 y 16.

Estos monumentos tallados presentan el topónimo (figura 8b) K'ihnha'nal, "lugar del agua caliente", un nombre que alude directamente a las características físicas del conjunto: las terrazas y la pirámide principal de El Duende están colocadas en línea hacia un manantial. K'ihnha'nal pudo ser el nombre de este cuerpo de agua y posteriormente se amplió como el nombre de todo este complejo arquitectónico (Stuart y Houston, 1994: 85). Lo que sí queda claro es que este topónimo aparece en los textos comisionados por Kokaaj K'awiil cohesionado a un sistema de culto local que con los años se convirtió en un programa políticoreligioso de la región, pues el ambicioso proyecto de El Duende nos permite entrever la forma en que Dos Pilas incorporó a su estructura el culto a diversas deidades a través de ritos y sacrificios.

\section{El liderazgo ritual}

La mención más temprana a K'inha'nal la encontramos en la Estela 1 (figura 9) en 9.13.15.0.0, 13 Ajaw 18 Pax, 27 de diciembre del 706 d. C., ocho años después de la entronización de Kokaaj K’awiil. Entonces el gobernante realizó, primero, un rito de tirar incienso (chokow ch'aaj) y después conmemoró la erección de la misma estela (tz'ahpaj).

Cinco años después, en la fecha 9.14.0.0.0, 6 Ajaw 13 Muwaan, 1 de diciembre del 711 d. C., se celebra, en la Estela 14 (figura 10a), el completamiento del décimo cuarto k'atuun a través una ceremonia de atadura de piedra, k'altuun, ${ }^{7}$ en K'inha'nal (en D2-E1) y una danza en un sitio denominado Yax Mutu'l (en F1), el mismo nombre de la ciudad de Tikal que, por la expresión uhtiiy, "ya ocurrió en", sabemos que fue un lugar dentro de Dos Pilas. El protagonista de la atadura de piedra y la danza fue Kokaaj K'awiil quien ordenó, en la misma fecha, el nacimiento del varón de los Dioses Remeros (H1-4, figura 10b). Esta cláusula nos indica que los ritos de los gobernantes, la invocación a deidades específicas, tuvieron como consecuencia el nacimiento de los dioses, en este caso, las deidades conocidas como Dioses Remeros.

\footnotetext{
${ }^{7}$ David Stuart (1996) ha señalado que los ritos de k'altuun, "atadura de piedra”, fueron rituales ligados específicamente a la erección de estelas. La palabra tuun no significa "año”, sino "piedra”, y sugiere que este rito fue adoptado por los mayas yucatecos y transformado en el sustantivo k'atuun, el periodo de veinte años, aproximadamente, que conocemos de las fuentes coloniales. Para el linguiista Otto Schumann (comunicación personal, 2011), esta propuesta es muy convincente.
} 


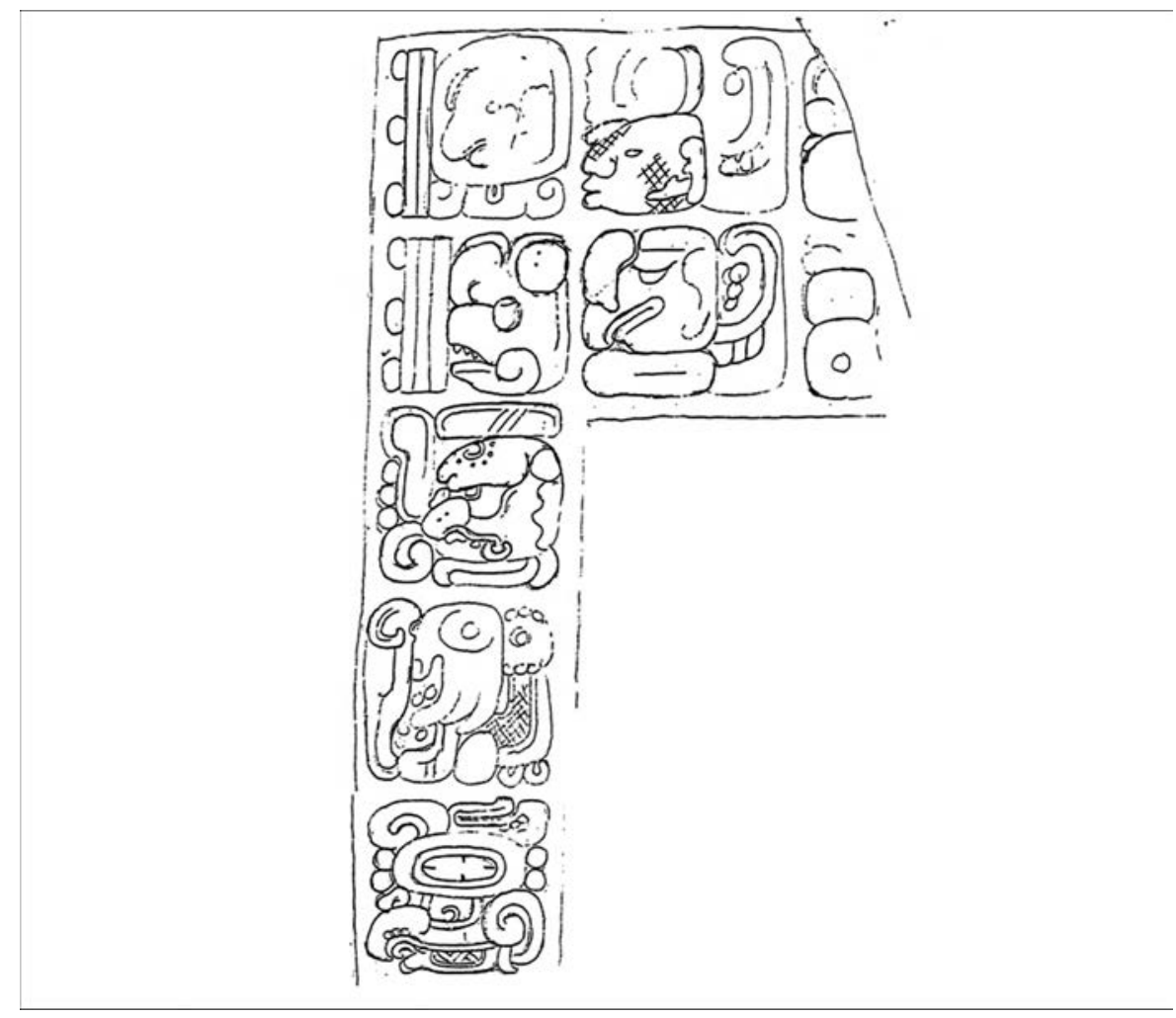

Figura 9. Texto superior de la Estela 1 de Dos Pilas. Dibujo cortesía de Alfonso Lacadena

Los ritos registrados en la Estela 14 dieron paso a otro evento registrado en la parte inferior de la estela (ver figura 7) ocurrido seis años después: el ataque a una localidad llamada Teel Naah en 8 Hix 2 Kumk'u, 9.14.5.3.14, 17 de enero del 717 d. C., que desembocó en la captura de un personaje representado atado y humillado a los pies de Kokaaj K'awiil.

Por otro lado, la Estela 11 (figura 11) celebra un nuevo periodo de ho' tuun en 9.14.5.0.0, 12 Ajaw 8 Kank'in, 4 de noviembre del 716 d. C., con un rito de tirar incienso y una danza realizada en la plaza central por Kokaaj K'awiil en compañía del "guardián de K'in B'ahlam", el hermano menor del gobernante. Como mencionamos antes, este derrotó a un señor tikaleño en el año 705 d. C. y sucedió a Kokaaj K'awiil en el trono.

Para el año 721 d. C., el liderazgo ritual de Kokaaj K'awiil de Dos Pilas en la región se hace evidente a través de un registro excepcional contenido en la Estela 15 (figura 12), el cual describe un "circuito de ritos" (Martin y Grube, 2008: 58) 


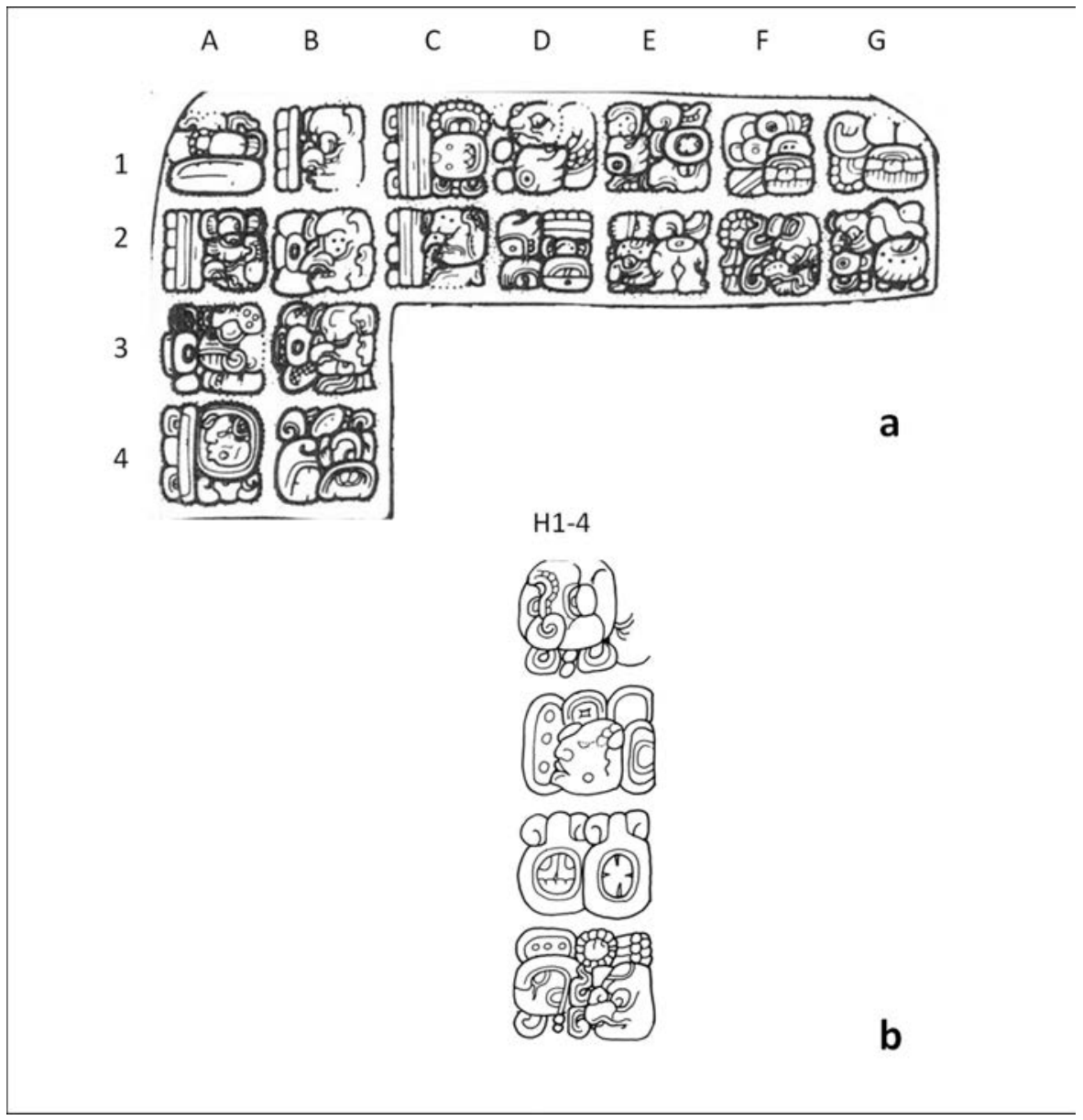

Figura 10. Textos de la Estela 14 de Dos Pilas. Dibujos de Houston, 1993

que se inician en la plaza principal de Dos Pilas con un rito de tirar incienso por parte de Kokaaj K'awiil en 9.14.10.0.0, 5 Ajaw 3 Mak, 9 de octubre del 721 d. C. Ese mismo día (figura 13a), las efigies de los dioses Gl y K’awiil fueron adornadas o embijadas (nahwaj uwin b'aahil) en el centro de la ciudad de Ceibal (Vega, 2009: 177-180: Velásquez, 2009: 440-444), un sitio ubicado sobre el margen izquierdo del río de la Pasión. Luego de ser adornadas las efigies de estas dos deidades, en la ciudad llamada K'ihnich Pa'witz, Aguateca (figura 13b), se erigió una estela dedicada a los mismos dioses (tz'ahpaj ulakamtunil "Gl" K'awiil, en C5-F1). Poco

${ }^{8}$ Recientemente, Alfonso Lacadena (comunicación personal, 2010) ha señalado que la vocal larga de la palabra tuun debe acortarse en las construcciones posesivas, como ulakamtunil. 


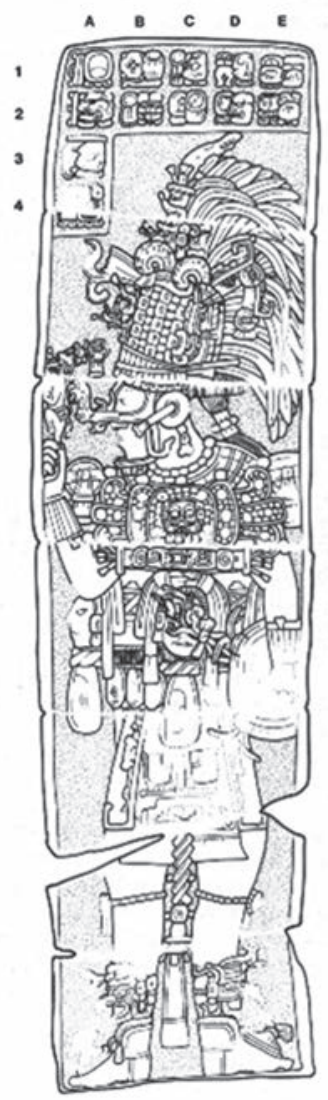

Figura 11. Estela 11 de Dos Pilas. Dibujo de Houston, 1993

más de dos winales (meses) después, en 7 Ajaw 3 K’ayab', 28 de diciembre del 721 d. C., Kokaaj K'awiil ató la Estela 15 (k'alaw tuun ${ }^{9}$ ) en K'inha'nal (figura 13c), y cierra el circuito de ritos con una danza realizada en la plataforma de la casa llamada Naah Chan, "Primer Cielo", en Dos Pilas (figura 13d), posiblemente el nombre del templo superior del complejo El Duende (en E2-F7).

El culto a las deidades GI y K'awiil se extendió en toda la región, pues tanto en Ceibal como en Cancuén encontramos interesantes referencias a ambos dioses. La señora de Cancuén que llegó a Dos Pilas, posiblemente la esposa de Kokaaj K'awiil y madre del gobernante K'awiil Chan K'ihnich, llevó el nombre

\footnotetext{
${ }^{9}$ Los ritos de k'altuun también se insertaron en los textos como expresiones verbales, tanto en voz activa, k'alaw tuun, "él ató la piedra", como en voz pasiva, k'ahlaj tuun, "la piedra fue atada".
} 


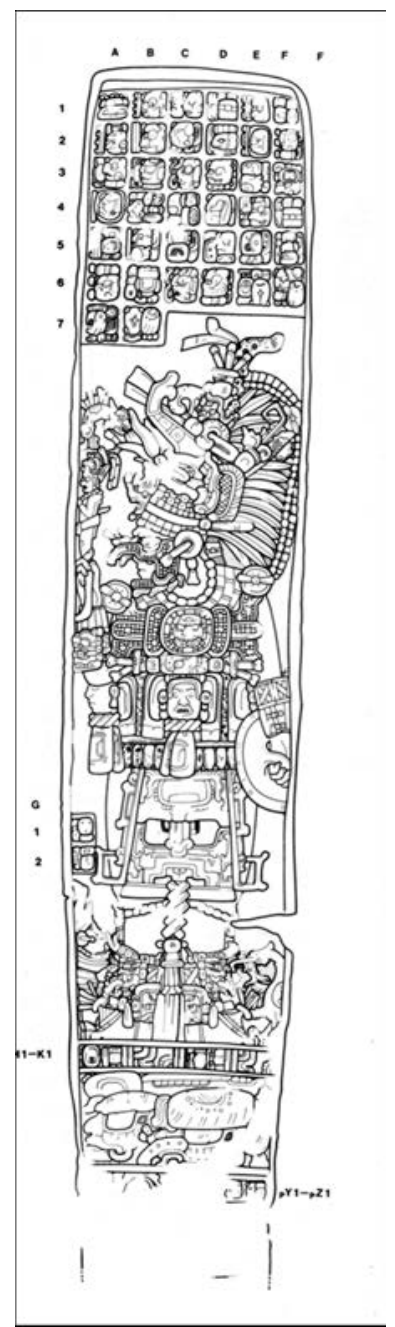

Figura 12. Estela 15 de Dos Pilas. Dibujo de Houston, 1993

de las deidades en su cláusula nominal. Por su parte, en Ceibal se realizaron ritos importantes del linaje local ante GI y K'awiil (cf. Tableros de la Estructura A-14 de Ceibal; Vega, 2009). Es interesante notar que el texto de la Escalera Jeroglífica de Tamarindito, donde se registró la derrota de K'awiil Chan K'ihnich de Dos Pilas en el año $761 \mathrm{~d}$. C. presenta, en la parte final —después de un evento de guerra aún oscuro- la expresión ukab'jiiy "Gl" K'awiil, "por orden de los dioses Gl y K'awiil”, lo que podría indicarnos que el discurso manejado en Tamarindito al momento de derribarse o abatirse las armas de Dos Pilas en la región ocurrió porque así lo ordenaron sus dioses. 


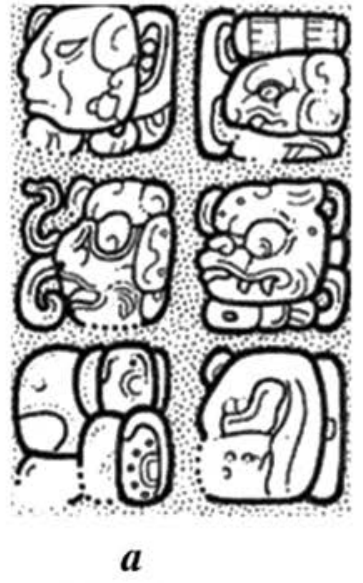

nahwaj uwin b'aahil "GI" K'awïl uhtïy tahn "Ceibal" ch'e'n

"las efigies de los dioses GI y K'awiil fueron adornadas. Ocurrió en la ciudad de Ceibal"

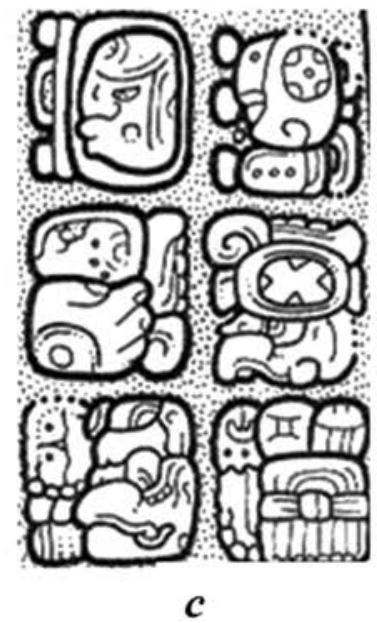

Wuk Ajaw Uhx K'anasïy k'alaw tuun K'in Ha'nal K'awiil Kokaaj k'uhul Mutul ajaw

'En 7 Ajaw 3 K'ayab', K'awiil Kokaaj, señor sagrado de Dos Pilas, ató la piedra en K'in Ha'nal". Naah Chan. Ocurrió en Dos Pilas".

Figura 13. Texto de la Estela 15 de Dos Pilas.

Dibujo de Houston, 1993 
Los ritos de la Estela 15 de Dos Pilas ocurrieron en el año $721 \mathrm{~d}$. C. Después de esa fecha, no encontramos en los textos de la ciudad otra referencia de actos protagonizados por Kokaaj K’awiil, quien murió cinco años después, a la edad de 53 años. La Estela 8 (figura 14) nos dice que en la fecha 11 Kawak 12 Mak, 9.14.15.1.19, 22 de octubre del 726 d. C., k'a'ay sak ? ik'il Kokaaj K'awiil k'uhul Mutu'l ajaw, "el blanco aliento de Kokaaj K'awiil, señor sagrado de Mutu'l, se extinguió". Cinco días después, por la noche, muhkaj tahn ch'e'n... Ha' uhx winikhaab' Kokaaj K'awiil yilaj waxak winik ajawtaak, “Kokaaj K'awiil, de tres k'atuunes, fue enterrado en el centro de la ciudad de Dos Pilas. Veintiocho señores lo han visto".

La cámara funeraria de K'awiil Kokaaj (figura 15) fue construida en la roca madre y sobre un piso de estuco, con un vano de acceso en su lado norte. Junto al cuerpo del gobernante fallecido se colocaron diversos moluscos, 23 falanges de felino, seis vasijas cerámicas, un tocado de mosaicos de concha y madre perla, conchas spondylus, orejeras, collares, brazaletes y otros artefactos de jadeíta (Demarest et al., 1991). Tanto el texto de la Estela 8 como el ajuar funerario de la Estructura L5-1, señalan que la ceremonia de entierro de Kokaaj K'awiil fue

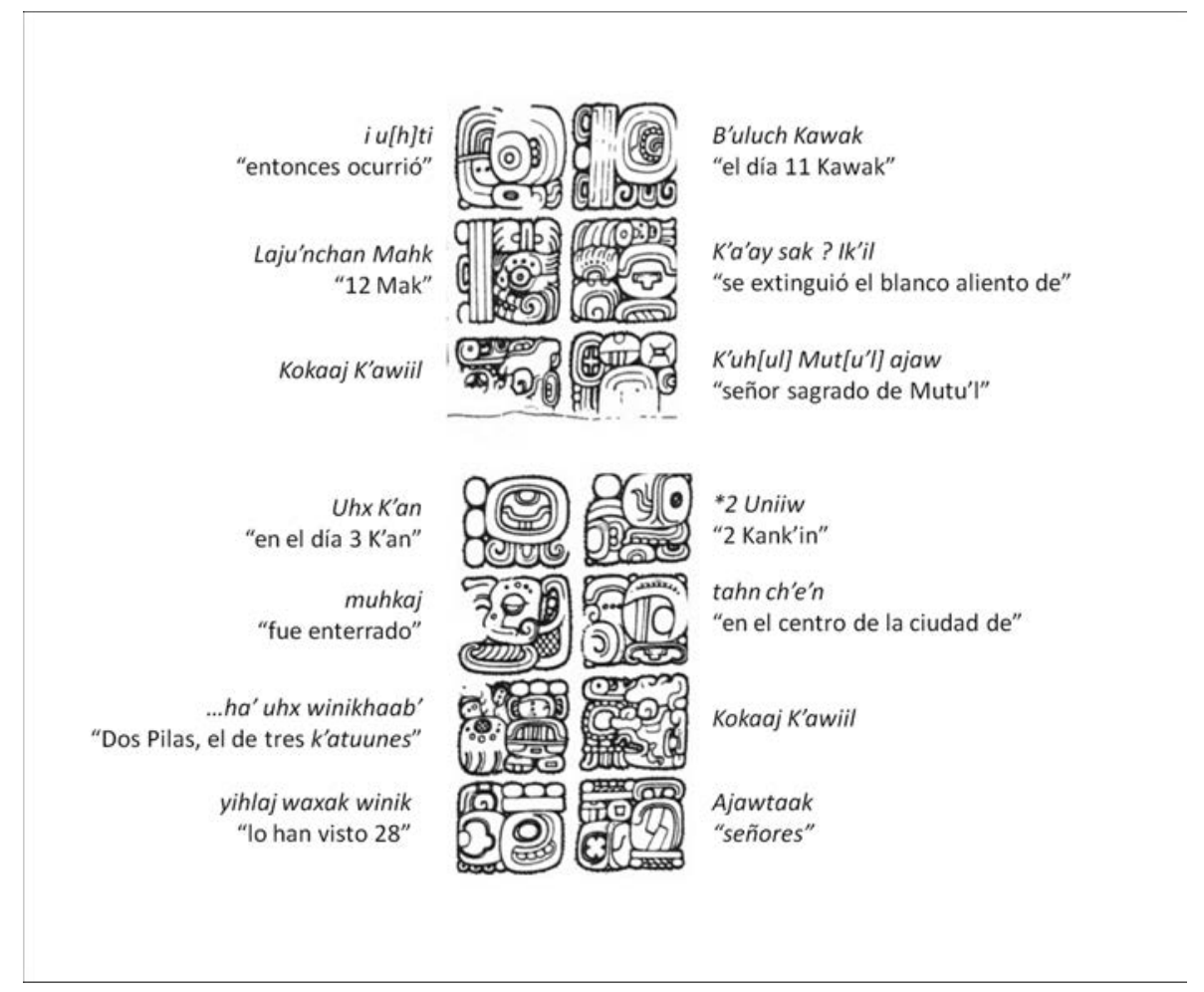

Figura 14. Texto de la Estela 8 de Dos Pilas que registra la muerte y entierro del gobernante Kokaaj K'awiil. Dibujo de Houston, 1993 


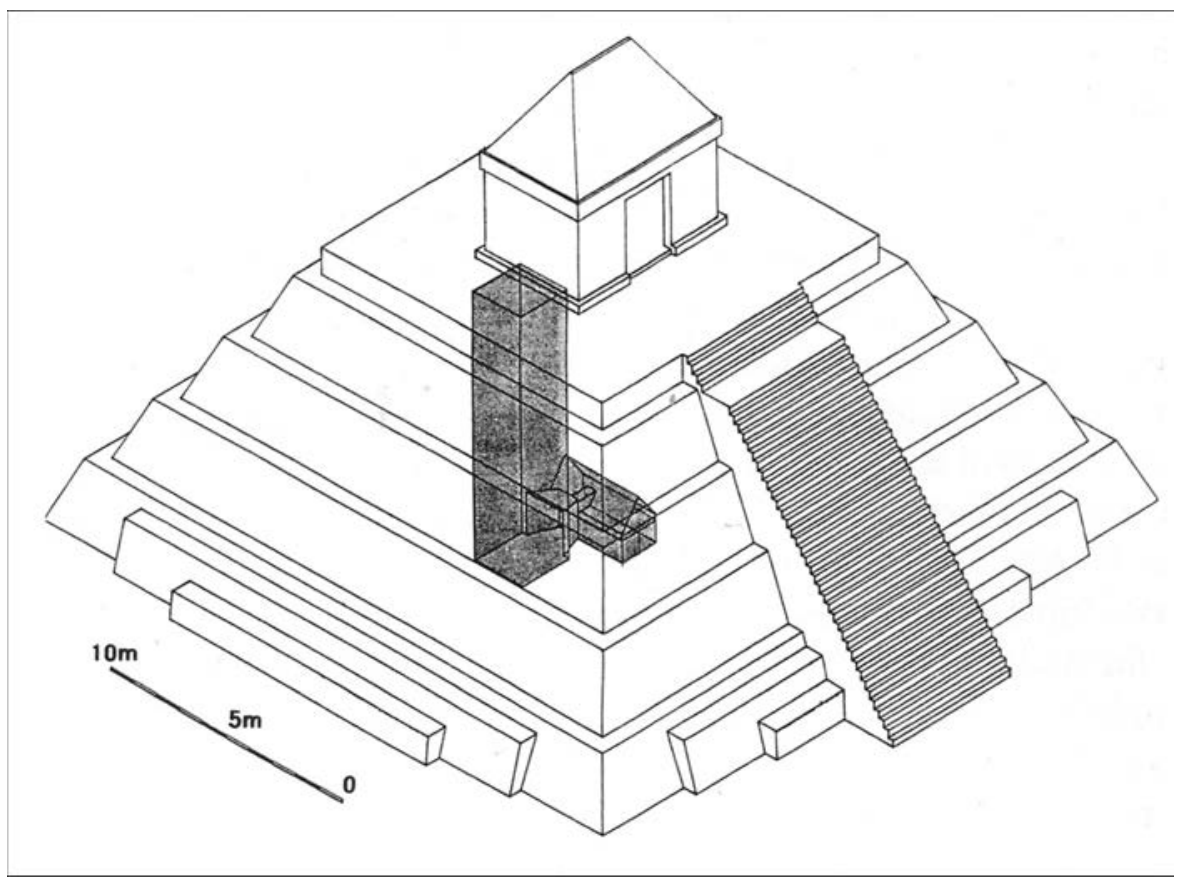

FiguRA 15. Estructura L5-1, cámara funeraria de Kokaaj K'awiil.

Tomado de Demarest, 2006

sin duda un evento notable, y los veintiocho señores que asistieron pudieron ser gobernantes de las ciudades de la región y miembros destacados de su corte.

Existe otra referencia al deceso de Kokaaj K'awiil en uno de los 37 huesos encontrados en la tumba del gobernante Jasaw Chan K'awiil de Tikal. En este texto se enlistan las fechas de muerte de numerosos miembros de nobleza extranjera, incluida la de Kokaaj K'awiil (figura 16): chami Kokaaj K'awiil aj...Ha', "Kokaaj K'awiil, el de Dos Pilas, murió". Como han notado Martin y Grube (2008: 59), Jasaw le negó el título de señor Mutu'l a K'awiil Kokaaj y lo identificó como "el de Dos Pilas", pues agregó al agentivo aj el topónimo de la ciudad, el cual no ha sido leído. Este registro se ha interpretado como un cierto reconocimiento por parte de Jasaw Chan K'awiil hacia su pariente, el gobernante de Dos Pilas.

Sin embargo, recientes estudios sobre el nagualismo realizados por Erik Velásquez (2009: 570-634) nos proporcionan una interesante mirada a esta referencia. Analizando de manera particular el término wahyis, ${ }^{10}$ que Velásquez

${ }^{10}$ El término wahyis ha sido traducido comúnmente como way o wayoob'. Sin embargo, estudios recientes (ver Velásquez García, 2009: 570-634) han mostrado que el sustantivo nagual o "espíritu familiar" era parte de un conjunto de términos para partes del cuerpo que, cuando no están acompañados por pronombres posesivos (ergativos) necesariamente requieren de un sufijo -is. Por lo tanto, la forma no pesesiva de uway o uwahy, "su nagual", "su espíritu familiar", es wayis o wahyis 


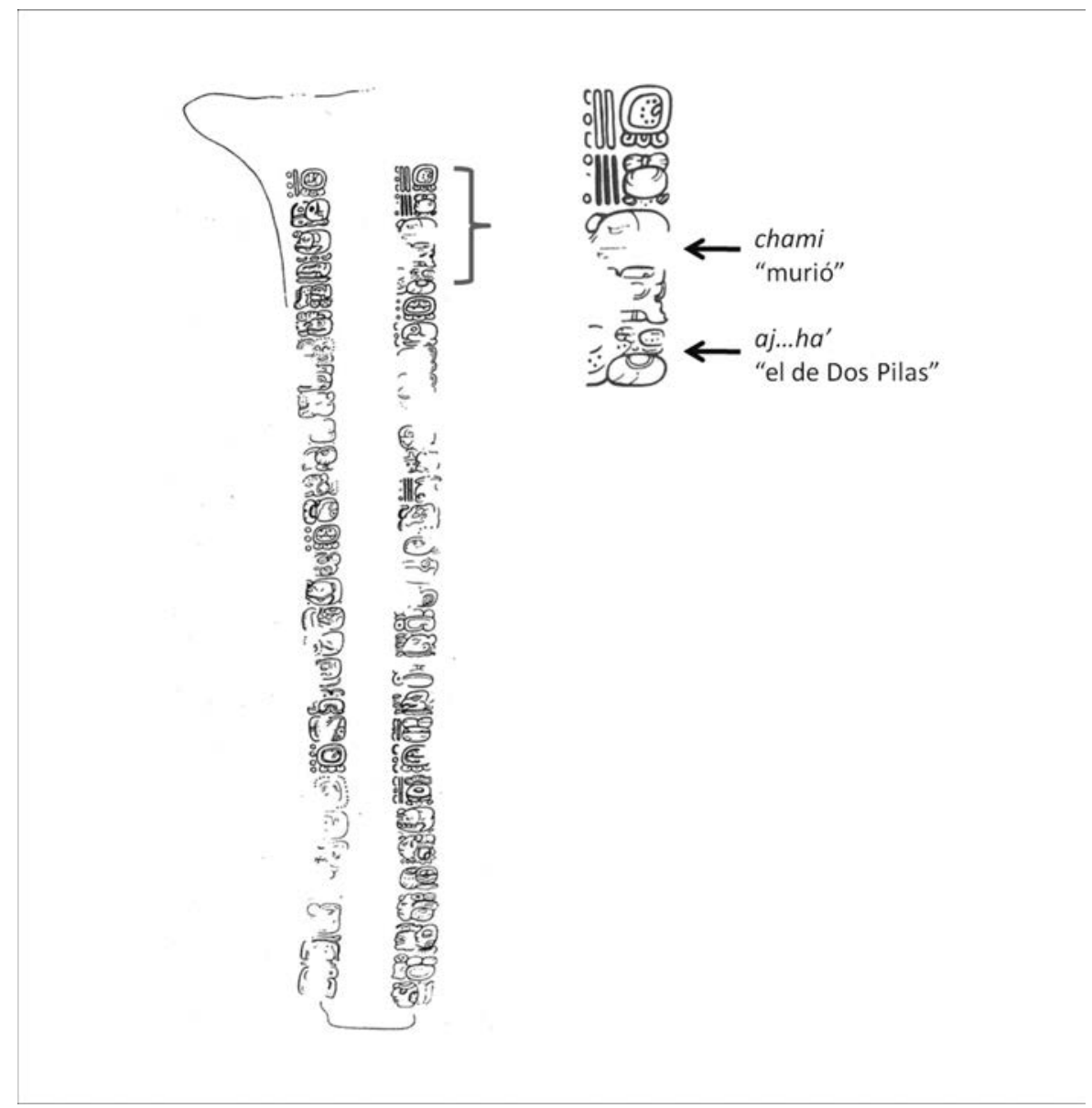

Figura 16. Texto Misceláneo 28, Entiero 116 de Tikal.

Dibujo de Houston, 1993

traduce como "espíritu familiar" (2009: 576), encontramos que fue una entidad anímica en particular, que se usó y externó a voluntad y que podía adquirirse desde el nacimiento o a través de peticiones específicas a lo largo de la vida. Los poseedores de esta entidad, durante el sueño profundo, enviaban a través de la boca a su wahyis para vigilar a sus enemigos y causarles daño a través de enfermedades durante la noche, cuando los destinatarios se encontraban más desprotegidos.

Los textos jeroglíficos evidencian que sólo unos cuantos señores eran poseedores de wahyis, pues señalan su importante estrato social, como el de k'uhul ajaw. Esta entidad estaba al servicio de su poseedor como aliado, el cual podía tener más de un wahyis, uno más poderoso que otro, con el propósito de atacar 
a los enemigos, pues si el wahyis de una persona era herido e, incluso, asesinado, el propietario sufría los mismos efectos.

El hueso tallado de Tikal depositado en la tumba 116 de Jasaw Chan K'awiil, el cual refiere una larga lista de muertes fechadas en ruedas de calendario, nos podría señalar las "victorias" que el gobernante tikaleño se adjudicó a través de su entidad wayhis, pues todas las localidades mencionadas en el hueso tenían o tuvieron cierta rivalidad con Tikal. En este contexto, la referencia a la muerte de Kokaaj K'awiil no estuvo en función de un reconocimiento póstumo, sino del triunfo de Jasaw sobre el gobernante de Dos Pilas que, nuevamente en el año 705 d. C., fue actor y testigo de la derrota de un señor de Tikal. Dentro de esta concepción, el wahyis de Jasaw fue más poderoso que el de Kokaaj K’awiil, una entidad vencida y asesinada en una experiencia onírica; esta trajo como consecuencia la enfermedad y posterior fallecimiento del señor de Dos Pilas.

\section{Un lugar de dioses, un lugar de culto}

A la edad de 25 años, Kokaaj K'awiil heredó de su padre un reino consolidado que, en gran medida, estuvo basado en la dignidad real de B'ajlaj Chan K'awiil, en sus éxitos militares y en su prolongado reinado. Las hazañas de B'ajlaj no sólo lo convirtieron en uno de los gobernantes más destacados de la región. También debieron representar un reto para su sucesor, pues Kokaaj K’awiil debía legitimarse a través de él y de su linaje, al mismo tiempo que luchaba por no crecer a la sombra de su padre.

Durante los primeros años de su reinado, Kokaaj K'awiil fue partícipe de otra derrota infringida a Tikal, una victoria que reafirmó el poderío bélico de Dos Pilas no sólo ante los señores de Tikal: también ante los diversos señoríos de la región. Es muy probable que este triunfo "liberara" en cierta medida a Kokaaj K'awiil, quien desde ese momento concentró sus esfuerzos en hazañas políticas que incorporaron la geografía natural de Dos Pilas, las cuevas, dentro de un complejo arquitectónico destacado. Aunque esta geografía fue utilizada desde los inicios de la ciudad - pues tenemos referencias de algunos ritos realizados por B'ajlaj Chan K'awiil dentro de una de las cuevas de Dos Pilas llamada Uhx Ajen ch'e'n, "la cueva de los tres amaneceres" ( $c f$. Escalón 1 de la Escalera Jeroglífica 4)_, con Kokaaj K'awiil se inauguró un programa político-religioso sin precedentes escritos en la región, pues este dignatario hizo de los circuitos rituales un sello distintivo de su reinado.

La importancia del complejo de El Duende dentro de las ceremonias de los señores de Dos Pilas no desaparece con la muerte de Kokaaj K'awiil, pues en el Panel 19 se registró un importante rito realizado por el joven K'awiil Chan K'ihnich, el hijo de Kokaaj K'awiil, el cual fue visto por veintiocho señores. La parte final del texto superior nos dice que la ceremonia ocurrió en "el lugar del agua caliente de Dos Pilas", en el complejo de El Duende. 
Como señalaron Stuart y Houston (1994: 86), el nombre de El Duende derivó de una característica natural de la región de Dos Pilas, la cual muestra que la geografía natural en muchos casos fue audazmente cohesionada con geografías artificiales, como lo muestran las estelas de Kokaaj K'awiil. El "lugar del agua caliente" no sólo conectó a diversos sectores sociales en las ceremonias y rituales: también incorporó ciudades dentro de un complejo político-religioso a través de danzas y ritos en honor de las deidades patronas. Dicho complejo vio nacer efigies de dioses y a una ciudad que supo aprovechar las características físicas de su zona para convertirse en un lugar de culto a nivel regional.

El estudio integral de los textos jeroglíficos de Kokaaj K'awiil revela una parte importante de la composición sociopolítica de la ciudad. Hemos visto que dentro del corpus de registros jeroglíficos de este gobernante sobresale un elemento político-ritual sólo mencionado en los trabajos sobre Dos Pilas de manera superficial: los "circuitos de ritos" (Martin y Grube, 2008), los cuales son una fuente de información social y religiosa muy importante. La religión es un sistema de acción y vida social, y los ritos constituyen una parte sobresaliente de este sistema, pues incidieron sobre la reproducción de la sociedad y muestran la derivación de diversos rasgos significativos (López Austin, 2002). En Dos Pilas tenemos registros de una serie de ritos realizados por el gobernante de este sitio en diversas ciudades de la región. Estos ritos incluyen danzas, colocaciones de estelas dedicadas a las deidades GI y K'awiil, aspersiones de incienso, entre otros.

Estos eventos, así como otras acciones políticas, han conducido a los especialistas a hablar del "reino Petexbatún" (Demarest, 2006), de una unidad política regional dominada por Dos Pilas (Houston y Mathews, 1985; Houston, 1993), de un estado regional que tuvo su capital en Dos Pilas (Martin y Grube, 2008). Sin embargo, a mi parecer, estos "circuitos de ritos" muestran una concepción estructurada del espacio desde un centro dinámico, que dotó de significaciones culturales propias a su entorno físico y el cual definió una geografía sagrada en donde los lugares de culto como plazas, templos y cuevas fueron vistos como sede de antepasados y dioses. En la región del río de la Pasión, esa capital fue Dos Pilas: un espacio significativo y profundamente vital que se extendió y consolidó - en las primeras décadas de su existencia- a través de las peregrinaciones o circuitos de ritos, los cuales a su vez articularon el ritmo y los momentos sagrados del ciclo ceremonial.

Los diversos ritos que encontramos descritos en varios textos de la región del río de la Pasión muestran que en las peregrinaciones cada sitio visitado - ya sea Aguateca, Ceibal o la misma Dos Pilas - fue el escenario de episodios rituales que convirtieron a estas ciudades en un centro cósmico. Aunque no existan evidencias jeroglíficas de peregrinaciones similares entre Dos Pilas y otras entidades del Petexbatún — como Tamarindito o Arroyo de Piedra-, no podemos descartar su realización.

Debido a que el ritual expresa, en las concepciones de López Austin (2001, 2002), una visión estructurada y coherente del mundo natural, de la sociedad y 
de la interrelación entre ambos, los nuevos estudios sobre la antigua ciudad de Dos Pilas deben, a mi parecer, considerar la organización social y las prácticas rituales como punto de partida para abordar la cosmovisión de esta entidad política con el fin de comprender la forma como esta ciudad se relacionó con los señoríos de la región, olvidando un poco la guerra.

En este artículo hemos analizado el ritual como acto colectivo en el que participaron las ciudades de la región del río de la Pasión a manera de sujetos sociales, vinculadas con distintas instituciones y estructuras de la sociedad. Sabemos que aún falta mucho por investigar, pero este enfoque nos permite conocer más detalladamente los mecanismos y estrategias político-religiosas de un señorío maya del periodo Clásico.

\section{BIBLIOGRAFÍA}

Boot, Erik

2002a "The Life and Times of B'alah Chan K'awil of Mutal (Dos Pilas), According to Dos Pilas Hieroglyphic Stairway 2", en Mesoweb <http://www.mesoweb. com/features/boot/DPLHS2.pdf> [Consultada el 1 de diciembre del 2012.]

2002b "The Dos Pilas-Tikal Wars from the Perspective of Dos Pilas Hieroglyphic Starway 4", en Mesoweb <http://www.mesoweb.com/features/boot/DPLHS4. pdf $>$ [Consultada el 1 de diciembre del 2012.]

2008 "At the Court of Itzam Nah Yax Kokaj Mut. Preliminary Iconographic and Epigraphic Analysis of a Late Classic Vessel", en Mayavase < http:/www.mayavase. com/God-D-Court-Vessel.pdf > [Consultada el 1 de diciembre del 2012.]

Brady, James E.

1994 "El impacto del ritual en la economía Maya”, VII Simposio de Investigaciones Arqueológicas en Guatemala, 1993, Juan Pedro Laporte y Héctor Escobedo (eds.). Guatemala: Museo Nacional de Arqueología y Etnología, 68-72.

1995 "Introducción: Proyecto Arqueológico Regional de Petexbatun de reconocimiento de cuevas", Proyecto Petexbatun, Informe Preliminar num. 6, Sexta Temporada 1994, Arthur Demarest, Juan Antonio Valdés y Héctor Escobedo, (eds.). Guatemala: Instituto de Arqueología e Historia de Guatemala, 523536.

1997 "Settlement Configuration and Cosmology: The Role of Caves at Dos Pilas", American Anthropologist, 99 (3): 602-618. American Anthropological Association <http://onlinelibrary.wiley.com/doi/10.1525/aa.1997.99.3.602/ abstract $>$ [Consultada el 1 de diciembre del 2012.]

Brady, James E., Ann Scott, Allan Cobb, Irma Rodas, John Fogarty y Mónica Urquizú Sánchez

1997 "Glimpses of the Dark Side of the Petexbatun Project. The Petexbatun Regional Cave Survey”, Ancient Mesoamerica, 8: 353-364. Cambridge: Cambridge University Press. 
Brady, James E. y Pierre R. Colas

2005 'Nikte' Mo' Scattered Fire in the Cave of K'ab Chante'. Epigraphic and Archaeological Evidence for Cave Desecration in Ancient Warfare", Stone Houses and Earth Lords. Maya Religion in the Cave Context, Keith M. Prufer y James E. Brady (eds.). Boulder: University Press of Colorado, 149-166.

Demarest, Arthur A.

2004 Ancient Maya. The Rise and Fall of a Rainforest Civilization. Londres: Cambridge University Press.

2006 The Petexbatun Regional Archaeological Project. A Multidisciplinary Study of the Maya Collapse, Nashville [Estados Unidos]: Vanderbilt University Press.

Demarest, Arthur, Héctor Escobedo, Juan Antonio Valdés, Stephen Houston, Lori Wright y Katherine Emery

1991 "Arqueología, epigrafía y el descubrimiento de una tumba real en el centro ceremonial de Dos Pilas, Peten, Guatemala”, U tzib', 1 (1): 14-28. Guatemala: Asociación Tikal.

Demarest, Arthur, Kim Morgan, Claudia Wolley y Héctor Escobedo

2003 "The Political Acquisition of Sacred Geography. The Murciélagos Complex at Dos Pilas", Maya Palaces and Elite Residences. An Interdisciplinary Approach, Jessica Joyce Christie (ed.), Austin: University of Texas Press, 120-152.

Escobedo, Héctor

1994 "DP40A: rescate arqueológico en la Estructura P6-1 de El Duende, Dos Pilas”, Proyecto Arqueológico Regional Petexbatun, Informe Preliminar num. 6, Sexta Temporada, 1994; Arthur A. Demarest, Juan Antonio Valdés y Héctor Escobedo (eds.). Guatemala: Instituto de Arqueología e Historia, 23-26.

Escobedo, Héctor, María Teresa Robles y Lori E. Wright

1992 "El Duende: Excavaciones en un sector ceremonial y habitacional del sitio de Dos Pilas, Petén”, IV Simposio de Investigaciones Arqueológicas en Guatemala 1990, Juan Pedro Laporte, Héctor Escobedo y Sandra Brady (eds.). Guatemala: Museo Nacional de Arqueología y Etnología, 119-124.

Fahsen, Federico

2002 "La Escalinata Número 2 de Dos Pilas, Petén. Los nuevos escalones”, Fundación para el Avance de los Estudios Mesoamericanos (Famsi), <http://www.famsi. org/reports/01098es/index.html> [Consultada el 1 de diciembre del 2012.]

Fahsen, Federico, Jorge Mario Ortíz, Jeannette Castellanos y Luis Fernando Luin

2003 "La Escalinata 2 de Dos Pilas, Petén: Los nuevos escalones”, XVI Simposio de Investigaciones Arqueológicas en Guatemala, 2002, Juan Pedro Laporte, Bárbara Arroyo, Héctor Escobedo y Héctor Mejía (eds.). Guatemala: Museo Nacional de Arqueología y Etnología, 679-692.

Guenter, Stanley P.

2003 “The Inscriptions of Dos Pilas Associated with B'ajlaj Chan K'awiil”, Mesoweb 
<http://www.mesoweb.com/features/guenter/DosPilas.pdf > [Consultada el 1 de diciembre del 2012.]

Houston, Stephen D.

1993 Hieroglyphs and History at Dos Pilas. Dynastic Politics of the Classic Maya. Austin: University of Texas Press.

Houston, Stephen D. y Peter Mathews

1985 The Dynastic Sequence of Dos Pilas, Guatemala. San Francisco: Pre-Columbian Art Research Institute.

Houston, Stephen D. y Takeshi Inomata

2009 The Classic Maya. Cambridge: Cambridge University Press, Cambridge World Archaeology.

Izquierdo, Ana Luisa y María Elena Vega

2009 "Dos Pilas en el Clásico tardío: un señorío regional”, ponencia presentada en el ciclo de conferencias titulado Investigaciones arqueológicas en la región Petexbatún y la zona del Río de la Pasión: nuevos datos, nuevas interpretaciones, en diciembre de 2009. México, Universidad Nacional Autónoma de México, Instituto de Investigaciones Filológicas.

López Austin, Alfredo

2001 "La religión, la magia y la cosmovisión", Historia Antigua de México, vol. IV: Aspectos fundamentales de la tradición cultural mesoamericana, Linda Manzanilla y Leonardo López Luján (coords.). México: Instituto Nacional de Antropología e Historia/Universidad Nacional Autónoma de México, Coordinación de Humanidades, Instituto de Investigaciones Antropológicas/Miguel Ángel Porrúa, 227-272.

2002 Breve historia de la tradición religiosa mesoamericana. México: Universidad Nacional Autónoma de México, Instituto de Investigaciones Antropológicas.

Mathews, Peter

2001 "Notes on the Inscriptions on the Back of Dos Pilas Stelae 8", The Decipherment of Ancient Maya Writing, Stephen D. Houston, Oswaldo Chinchilla y David Stuart (eds.). Norman: University of Oklahoma, 394-415.

Martin, Simon

2006 "Cacao in Ancient Maya Religion: First Fruit from the Maize Tree and other Tales from the Underworld", Chocolate in Mesoamerica: A Cultural History of Cacao, C. L. McNeil (ed.). Gainsville: University Press of Florida, 154-183.

Martin, Simon y Nikolai Grube

$2000 \quad$ Chronicle of Maya Kings and Queens. Deciphering the Dynasties of the Ancient Maya. Londres: Thames and Hudson.

2008 Chronicle of Maya Kings and Queens. Deciphering the Dynasties of the Ancient Maya, 2a. edición. Londres: Thames and Hudson. 
Stuart, David

1996 "Kings of Stone: A Consideration of Stelae in Ancient Maya Ritual and Representation”, Res. Anthropology and Aesthetics, 29/30, Spring/Autumn: 148171. Cambridge: Harvard University, Peabody Museum of Archaeology and Ethnology.

Stuart, David y Stephen D. Houston

1994 Classic Maya Place Names, Washington D.C.: Dumbarton Oaks Research Library and Collection (Studies in Pre-Columbian Art and Archaeology, 33).

Vega Villalobos, María Elena

2009 "La historia de Ceibal en la época Clásica”, tesis de maestría en Estudios Mesoamericanos. México: Universidad Nacional Autónoma de México, Facultad de Filosofía y Letras, Instituto de Investigaciones Filológicas.

Velásquez García, Erik

2009 "Los vasos de la entidad política de 'Ik': una aproximación histórico-artística. Estudio sobre las entidades anímicas y el lenguaje gestual y corporal en el arte maya Clásico", tesis de doctorado en Historia del Arte. México: Universidad Nacional Autónoma de México, Facultad de Filosofía y Letras, Instituto de Investigaciones Estéticas. 